\title{
Innovation Diffusion of Wearable Mobile Computing: Pervasive Computing Perspective
}

\author{
By Syakirah Mohamad Taib, Rebecca De Coster, Janerose Nyamu \\ College of Engineering, Design and Physical Science \\ Brunel University London, UK
}

\begin{abstract}
Wearable technology has become mainstream in this information age, it is needed to understand how the potential users of this emerging technology gain value from the innovation of the technology, consequently increasing users' diffusion. Extant literature on the acceptance of mobile computing has been developing such as in mobile banking services and in healthcare service, however, the study of users' acceptance about the emergence of wearable mobile computing is still at the early stages. This paper examines the development of a conceptual framework to understand the technology adoption factors for wearable mobile computing utilizing the Technology Acceptance Model (TAM), the Diffusion of Innovation Theory (DOI) and related factors on mobility and pervasive computing. Data of 272 respondents were collected using quantitative approach of survey based questionnaires conducted in Malaysia. The findings of this research revealed the factors of mobility (MOB), personalization (PN) and perceived enjoyment (PE) achieved the highest average score by respondents, followed by perceived usefulness (PU) and perceived ease of use (PEU), observability (OBS), facilitating condition (FC) and social influence (SI). As wearable technology is perceived to be pervasive, mobility (MOB) and perceived enjoyment (PE) contribute the dominant factor for usage acceptance, while Perceived Usefulness (PU) from established model TAM, still plays an important factors in predicting innovation adoption of wearable mobile computing.
\end{abstract}

Keywords

Wearable mobile computing, Pervasive computing, Wearable Technology, Adoption, Mobility

\section{INTRODUCTION}

Wearable mobile computing an emerging technology has become a vision of "Pervasive Computing", where people may access to computing anywhere anytime. Wearable technology is expected to grow in this digital age, however, there are limited studies to investigate the innovation and diffusion of wearable mobile computing and usage decisions, moreover, the deployment of this technology innovation is still at its infancy stage. It is imperative to understand how the potential users of the emerging technology gain value from the innovation of the technology, consequently increasing users' diffusion and global market acceptance. The phenomena of mobile phones in our daily activities has reached the mass adoption 
especially in Malaysia context [1], mobile services such as mobile internet, mobile banking, online shopping, media socializing and internet surfing have become common daily activities. Studies on acceptance of mobile computing has been developing such as in mobile banking services and in healthcare service, however, the study of users' acceptance about the emergence of wearable mobile computing is still at the early stages [2]. Reference [3], wearable computing has built-up research opportunities in artificial intelligence, mobile computing, or in human computer interaction. Wearable mobile computing will gain value from the vision of Pervasive Computing, as in [4] stated "the most profound technologies are those that disappear".

\section{THEORETICAL BACKGROUND AND CONCEPTUAL FRAMEWORK}

\section{A. Wearable Mobile Computing}

Wearable computing which refers to electronic technologies embedded worn on the human body [5] as unobtrusively as apparel such as a smart watch continuously providing an interface to many computing tasks with the mobile smartphones acting as a hub [2]. There are various applications of wearable mobile computing for instance healthcare and monitoring system, fitness and wellness, infotainment, military and industrial; a lot of wearable devices emerged in the market includes Apple iWatch, iRing, Sony Smart Band, Google Glass, Bluetooth Ring, and smart contact lenses for medical purposes [3]. The emergence of wearable mobile computing will accelerate the development of pervasive computing technologies and become a challenge in information technology research. The perceived value of this technology could not be fully realised until it is accepted and adopted by potential users which is the main focus of this research.

\section{B. Pervasive Computing}

The purpose of wearable mobile computing is providing a computing services anytime and anywhere, which is necessary element of pervasive computing. Reference [4] had stated that "the concept of pervasive or ubiquitous computing as invisible, context-aware, embedded technology that will serve users in seamless and unconscious interaction”. Pervasive means "existing everywhere” embedded, nomadic, adaptable, intentional, eternal, and powerful while being efficient [6].

Findings from this study could be applied as valuable insight for the future innovation in designing new wearable mobile computing in pervasive computing environment due to some of the potential users may adopt wearable technology with different reasons. Pervasive computing is anytime, everywhere concept permitting access ranging from mobile phones to computing units embedded into daily objects, including barcodes, RFID, PDAs (personal digital assistants) and wireless communications [5], wearable computing are unique opportunities with the potential to commence wide spread adoption of Pervasive computing by embedding computers in many daily life items such as clothing, glasses, and other wearable objects. 


\section{Conceptual Framework}

Various frameworks and models from many researchers utilised Technology Acceptance Model (TAM) to explain the technology acceptance in information technology (IT). There are also a number of different existing frameworks and predictive models in the literature for instance the ubiquitous computing acceptance model [7] and the factors of mobile computing [8]. Due to limited research concerning about technology innovation acceptance of mobile computing and wearable technology, this study was designed to develop the conceptual framework based on the integration factors from the Technology Acceptance Model (TAM), the Diffusion of Innovation Theory (DOI) and related factors on mobility and ubiquity of technology to understand the wearable technology acceptance. The factors from the TAM introduced by [9] are perceived usefulness (PU) and perceived ease of use (PEU), observability is selected from DOI [10], moreover, other selected factors for this research are mobility (MOB), personalization (PN), facilitating condition (FC) and perceived enjoyment (PE) as integrated factors, while social influence (SI) and application space as the determinants of key constructs which may affect the factors predicted. The proposed conceptual framework is shown in Fig. 1. The contribution of this study is the integration of the established model (TAM and DOI) with related proposed factors from mobile technology factor, pervasive/ubiquitous factors to evaluate potential user usage acceptance, thus promising the diffusion of innovation.

The development of the constructs (factors) for this research were selected from related literature and adapted to the context of wearable mobile computing from pervasive perspective, as shown in Table I.

\section{RESEARCH APPROACH}

The respondents are the university students and employed personnel as the potential adopters, clustered from the central and southern region of Malaysia by utilizing clustering sampling based on the characteristic of prior internet knowledge and experience in mobile technology. Cluster sampling is a sampling technique cover a large geographical area while the sampling frame is not available [19]. The data collection was conducted from Dec 2015-Feb 2016, after the research approval from Brunel University Research Ethic committee had been granted. Table II shows the sample profile for this study.

This research employed survey based self-administered questionnaires (quantitative approach) with five-Point Likert scales, indicates the extent of agreement where $1=$ strongly disagree to $5=$ strongly agree adapted from literature. Malaysia is divided into six main regions: Northern Region, Central Region, Southern Region, East Coast, Sabah and Sarawak. The sample size of 272 were collected from Central and Southern Region, with $33.5 \%$ male and $66.5 \%$ of female, age group of $18-25$ contributed the largest sample of $60.7 \%$ and the least is age group $45-54$ with $3.3 \%$. 
The reliability of questionnaire has been tested using SPSS version 20 to check the scale's internal consistency. The Cronbach alpha coefficient should be above 0.70 [20] and the Table III shows all the factors chosen above the suggested value and acceptable for further statistical analysis. Correlation is used to describe the strength and direction of the relationship between two variable. The strength of the relationship ranging from $r=.01$ to 0.29 (small), $r=0.30$ to 0.49 (medium) and $r=0.50$ to 1.0 (large) [20]. Again, Table III shows the Pearson, r correlation of dependent construct Behavioral intention (BI) between independent constructs (SI, PU, PEU, OBS, MOB, FC and PE), there was a positive correlation of the all factors selected indicates the positive relationship. From multiple regression test, the results showed Perceived Usefulness (PU), Mobility (MOB) linked factor with Observability (OBS), Perceived Enjoyment (PE) linked factor with Personalisation (PN) and Facilitating Condition (FC) are the significant predicted factors for potential users to adopt the wearable mobile technology with $61 \%$ of variance explained in $\mathrm{BI}$.

\section{RESEARCH FINDINGS AND DISCUSSION}

The selected factors of social influence (SI), perceived usefulness (PU), perceived ease of use (PEU), observability (OBS), mobility (MOB), facilitating condition (FC), perceived enjoyment (PE) and personalization (PN) were analyzed based on gender (Fig. 2), age (Fig. 3) and based on position (Fig. 4). The model factor score differences based on gender in Fig. 2 shows that MOB, PN and PE contributed to the highest average score for both male and female followed by PU, PEU (the two TAM factors), OBS, FC and then lastly SI. The factor scores difference based on age in Fig. 3, also shows that MOB, PE and PN have the highest average score followed by PU however, age group 36-44 contributed the highest average score for OBS, MOB and $\mathrm{PE}$, which may reflect the priorities of people at midcareer stage.

For the factor scores difference based on position in Fig. 4, only 2 group are included in the study as under the group 'others' only has 2 respondents (retained for the completeness of data collection). Again, result shows that MOB, PE and PN has the highest average score for both group: employed personnel and students. The outcome which is behavioral intention or the usage acceptance of wearable technology was analyzed based on age and gender in Fig. 5 shows that the highest average score is for two age group 18-26 and 27-35 while male has the highest average score compared to female for age group 36-44. This findings demonstrate that younger age are more likely to accept the technology innovation, in contrast female at older age are shown to be also more likely to adopt this emerging technology compared to male. 


\section{CONCLUSION}

From this study, a conceptual framework has been developed with the predicted factors for potential users to adopt the wearable mobile computing in Malaysia. The conceptual framework developed underpinning this study composed the established models integrated with the mobility and pervasive computing factors to understand the impact of the innovation of the new enabling technology. The empirical data studied to examine the model factors through comparing average score and regression testing. Malaysia as a developing country may adopt new emerging technology for beneficial of daily activities in this challenging information society.

According to the results, MOB, PE and PN are the dominant predicted factors for potential users to adopt the wearable mobile technology with the highest average scores for factor differences in gender, age and position. As wearable technology is perceived to be pervasive, mobility (MOB) and perceived enjoyment (PE) contribute the dominant factor for usage acceptance while Perceived Usefulness (PU) from established model TAM, still plays an important factors in predicting innovation adoption of wearable mobile computing. From Multiple regression test, Perceived Usefulness (PU) indicating the largest unique contribution, followed by Mobility (MOB) linked factor with Observability (OBS), Perceived Enjoyment (PE) linked factor with Personalisation (PN) and Facilitating Condition (FC) are the significant predicted factors with $61 \%$ of variance explained of users' acceptance of wearable mobile technology. Therefore, these predicted factors may positively influence innovation diffusion of wearable mobile technology in Malaysia.

\section{REFERENCES}

[1] M. A. Osman, A. Zawawi Talib, Z. A. Sanusi, T. S. Yen, and A. S. Alwi, “An exploratory study on the trend of smartphone usage in a developing country," in Digital enterprise and information systems, Springer Berlin Heidelberg, 2011, pp. 387-396.

[2] J. Wei, "How Wearables Intersect with the Cloud and the Internet of Things," IEEE Consumer Electronics Magazine, pp. 53-56, 2014.

[3] S. Jhajharia, S. K. Pal, and S. Verma, "Wearable Computing and its Application,” Int. J. Comput. Sci. Inf. Technol., vol. 5, no. 4, pp. 5700-5704, 2014.

[4] M. Weiser, “The Computer for the 21st Century,” Scientific American, vol. 265, no. 3. pp. 94-104, 1991.

[5] C. J. Anumba and X. Wang, "Mobile and Pervasive Computing in Construction: An Introduction,” Mob. Pervasive Comput. Constr., vol. 1, pp. 1-10, 2012.

[6] G. Pour, "Software engineering for pervasive computing: An outlook for educational reform," in 5th IEEE/ACIS International Conference on Computer and Information Science and 1st IEEE/ACIS International Workshop on Component- 
Based Software Engineering, Software Architecture and Reuse (ICIS-COMSAR'06). IEEE, 2006, pp. 168-173.

[7] S. Moran, T. Nishida, and K. Nakata, "Comparing British and Japanese perceptions of a wearable ubiquitous monitoring device,” IEEE Technology and Society Magazine, vol. 32, pp. 45-49, 2013.

[8] T. M. Faziharudean and T. Li-Ly, "Consumers' behavioral intentions to use mobile data services in Malaysia,” African J. Bus. Manag., vol. 5, no. 5, pp. 18111821, 2011.

[9] F. D. Davis, "Perceived usefulness, perceived ease of use, and user acceptance of Information Technology,” MIS Q., 1989.

[10] E. M. Rogers, Diffusion of Innovations, Fourth Ed. The Free Press, New York, 1995.

[11] I. M. Al-Jabri and M. S. Sohail, "Mobile banking adoption: application of diffusion of innovation theory,” J. Electron. Commer. Res., vol. 13, no. 4, pp. 379391, 2012.

[12] C. Kim, "Factors Influencing the Usage of Ubiquitous-Based Mobile Devices," in Computing Technology and Information Management (ICCM), 2012 8th International Conference, 2012, pp. 2-7.

[13] S. Y. Ho, “The effects of location personalization on individuals' intention to use mobile services,” Decis. Support Syst., vol. 53, no. 4, pp. 802-812, Nov. 2012.

[14] K. A. Saeed, "Understanding the adoption of mobile banking services : An empirical assessment,” in AMCIS, 2011.

[15] K. Yang, “Consumer technology traits in determining mobile shopping adoption: An application of the extended theory of planned behavior," J. Retail. Consum. Serv., vol. 19, no. 5, pp. 484-491, Sep. 2012.

[16] D. Tojib and Y. Tsarenko, "Post-adoption modeling of advanced mobile service use,” J. Bus. Res., vol. 65, no. 7, pp. 922-928, Jul. 2012.

[17] C.-S. Yu, "Factors affecting individuals to adopt mobile banking: Empirical evidence from the UTAUT Model,” J. Electron. Commer. Res., vol. 13, pp. 104-121, 2012.

[18] H.-Y. Wang, C. Liao, and L.-H. Yang, "What Affects Mobile Application Use? The Roles of Consumption Values,” Int. J. Mark. Stud., vol. 5, pp. 11-22, 2013.

[19] Z. Awang, Research methodology and data analysis, 2nd ed. Shah Alam, Malaysia: UiTM Press, 2012.

[20] J. Pallant, SPSS Survival: A step by step guide to data analysis using IBM SPSS, 5th ed. New York, USA: The McGraw.Hill Companies, 2013. 


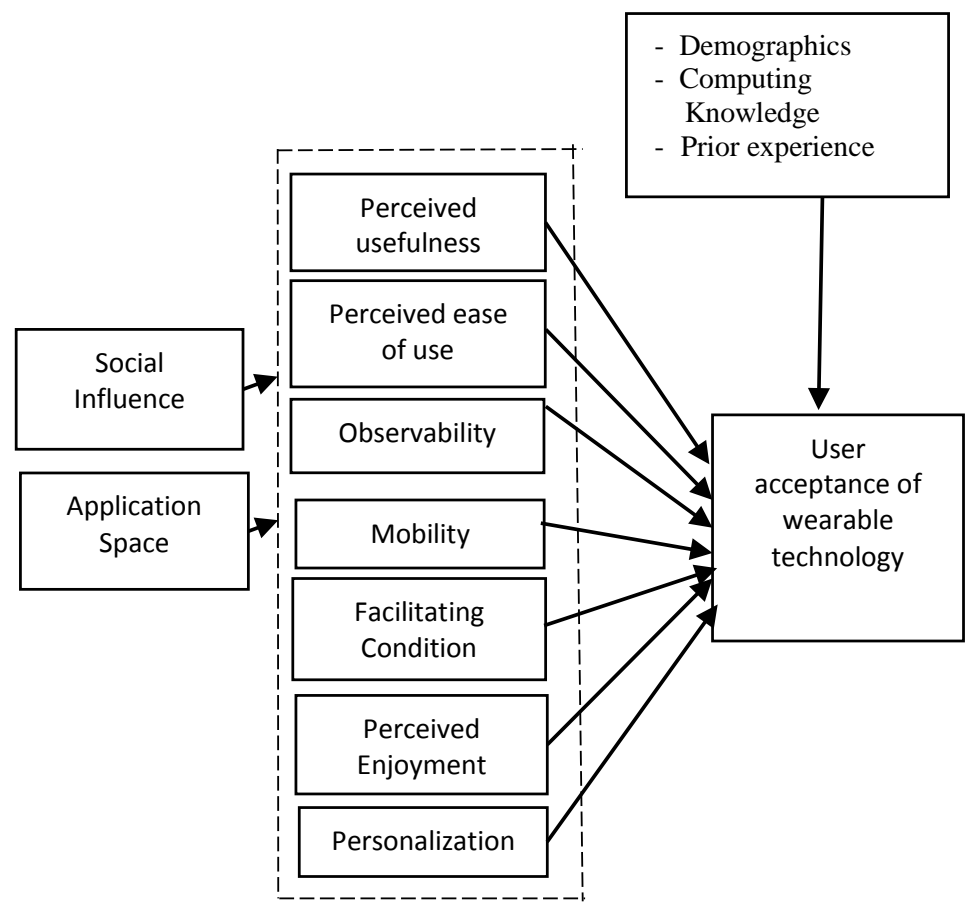

Figure 1. The conceptual framework of wearable technology

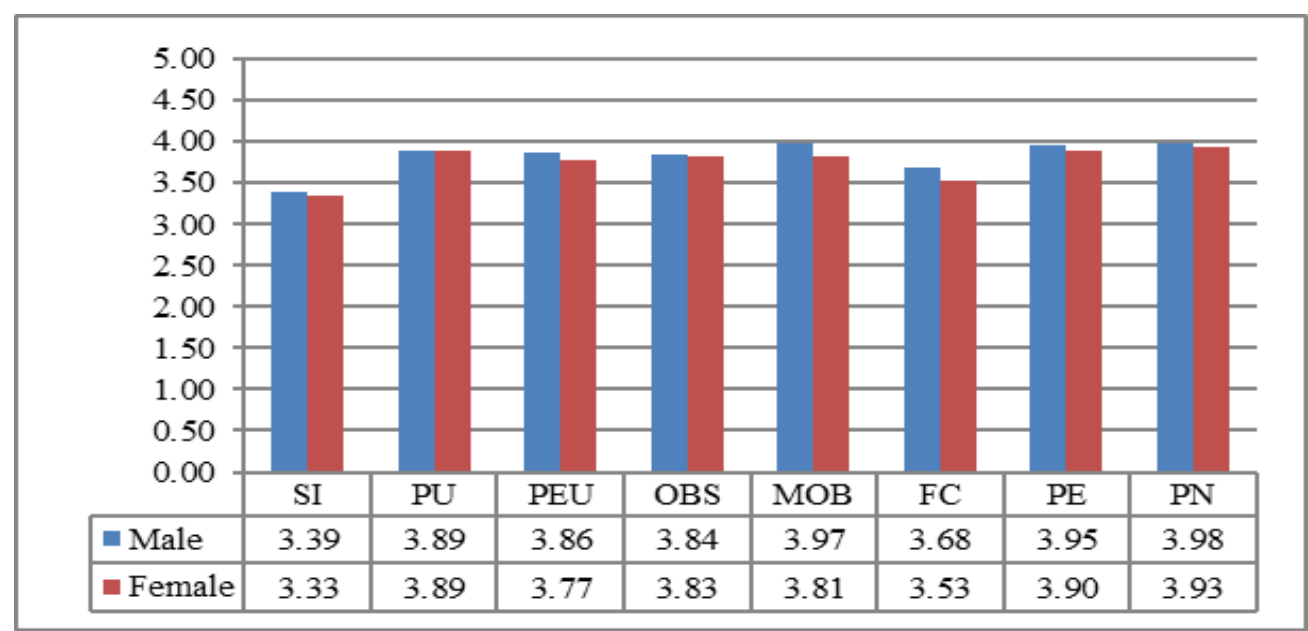

Figure 2. Factor scores difference based on gender 


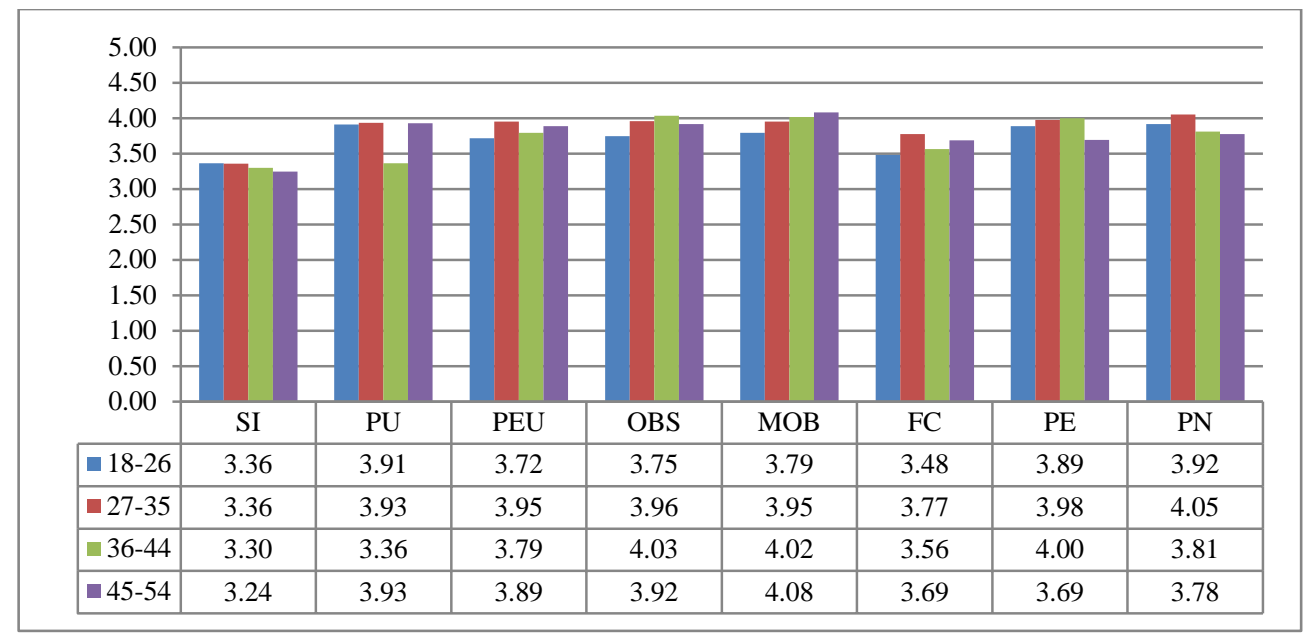

Figure 3. Factor scores difference based on age

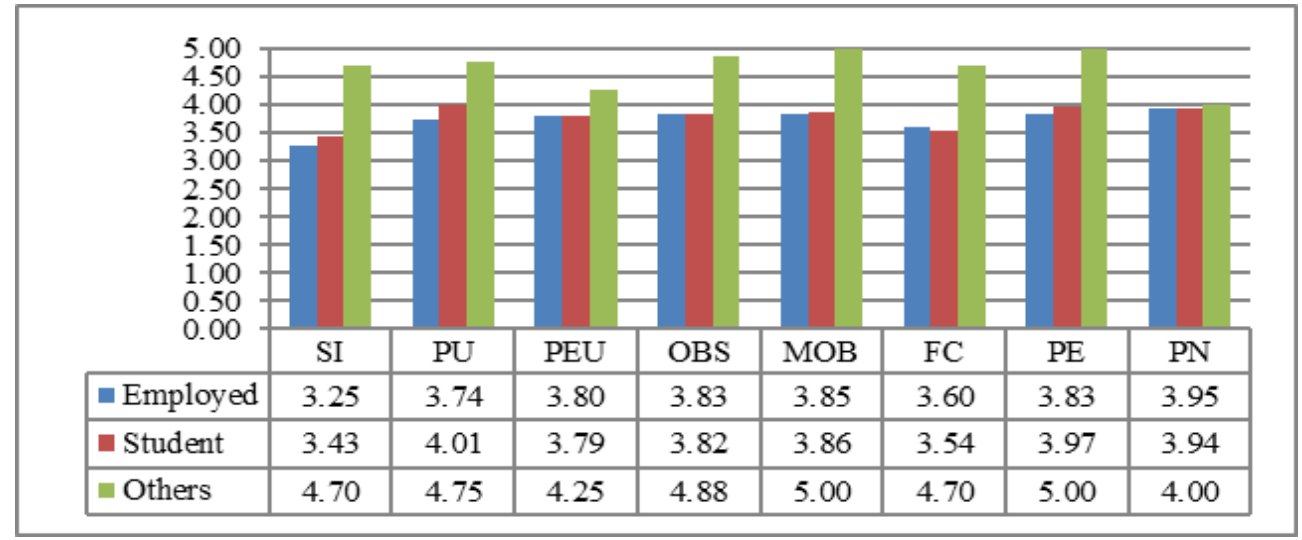

Figure 4. Factor score difference based on position

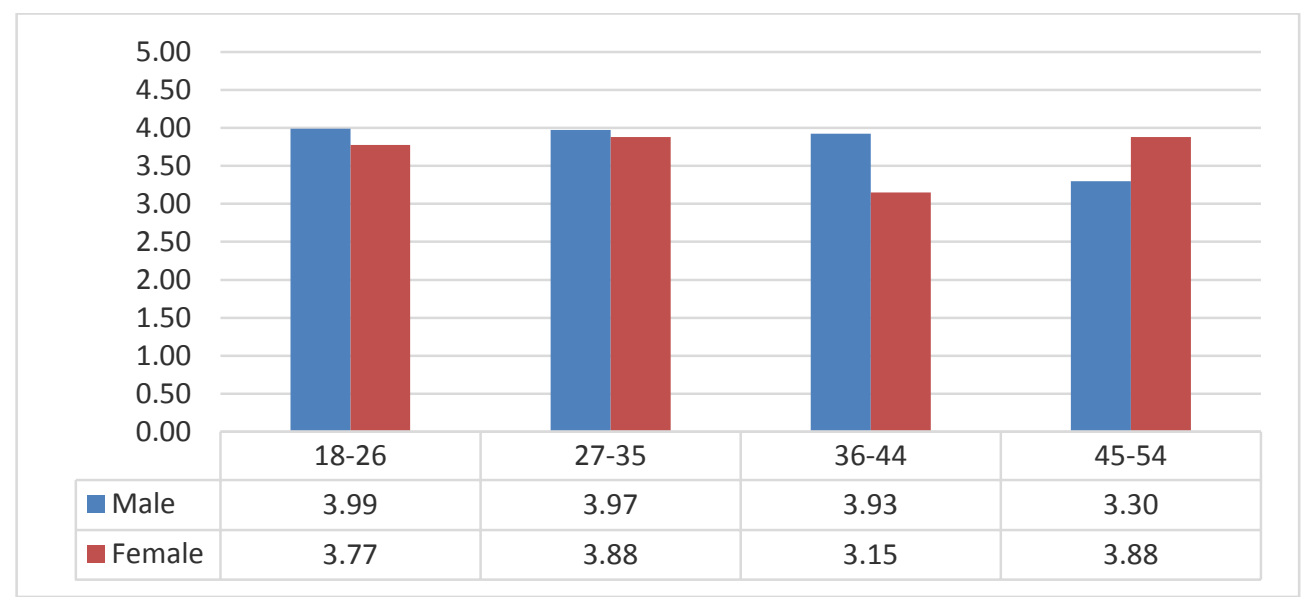

Figure 5. Behavioral intention average scores based on age and gender 
i-Society 2016 Conference

TABLE I. Factors developed in the conceptual framework

\begin{tabular}{|c|c|c|}
\hline Factors & Definition & $\begin{array}{l}\text { Theories/ Factor } \\
\text { adapted }\end{array}$ \\
\hline $\begin{array}{l}\text { Perceived } \\
\text { Usefulness }\end{array}$ & $\begin{array}{l}\text { Perceived usefulness as the extent to which an } \\
\text { individual believes that using a specific system } \\
\text { would improve his or her job performance. }\end{array}$ & $\begin{array}{l}\text { Technology } \\
\text { Acceptance Model } \\
\text { (TAM) [9] }\end{array}$ \\
\hline $\begin{array}{l}\text { Perceived Ease } \\
\text { of Use }\end{array}$ & $\begin{array}{l}\text { Perceived ease of use as the degree to which an } \\
\text { individual believes that using a particular system } \\
\text { would be free of effort. }\end{array}$ & \\
\hline Observability & $\begin{array}{l}\text { Observability is the degree of making visible the } \\
\text { results of innovation. }\end{array}$ & $\begin{array}{l}\text { Diffusion of } \\
\text { Innovation Theory } \\
\text { (DOI) }[10][11]\end{array}$ \\
\hline Mobility & $\begin{array}{l}\text { Mobility is the factor for mobile computing to } \\
\text { provide pervasive and ubiquitous connection in } \\
\text { encouraging users' behavioral intention to use the } \\
\text { services }\end{array}$ & {$[8][12]$} \\
\hline Personalization & $\begin{array}{l}\text { Personalization as the ability to customise } \\
\text { wearable technology services to fit the user's } \\
\text { preferences. }\end{array}$ & [12][13][14] \\
\hline $\begin{array}{l}\text { Facilitating } \\
\text { Condition }\end{array}$ & $\begin{array}{l}\text { Facilitating Condition is defined as the degree to } \\
\text { which an individual believes that the conditions } \\
\text { exist which gives them control (or choice) over } \\
\text { whether they perform a behavior. }\end{array}$ & [7] [11][14] \\
\hline $\begin{array}{l}\text { Perceived } \\
\text { Enjoyment }\end{array}$ & $\begin{array}{l}\text { Perceived enjoyment is defined as an interesting, } \\
\text { fun, enjoyable, and entertaining to adopt wearable } \\
\text { technology. }\end{array}$ & {$[8][15][16]$} \\
\hline Social Influence & $\begin{array}{l}\text { Social influence is defined as a user's perception } \\
\text { that most people who are important to him think } \\
\text { he should or should not perform the behavior }\end{array}$ & [8] [17] \\
\hline $\begin{array}{l}\text { Application } \\
\text { Space }\end{array}$ & $\begin{array}{l}\text { Mobile application usage with a program designed } \\
\text { that runs on a mobile device (smart phone, tablet) } \\
\text { operated by the owner of the mobile operating } \\
\text { system, such as the Apple App Store, Google } \\
\text { Play, to access the mobile services }\end{array}$ & [18] \\
\hline
\end{tabular}


TABLE II. SAMPLE PROFILE

\begin{tabular}{|c|c|c|c|}
\hline \multicolumn{2}{|c|}{ Characteristic N=272 } & Frequency & $\begin{array}{c}\text { Percent } \\
\text { (\%) }\end{array}$ \\
\hline \multirow{2}{*}{ Gender } & Male & 91 & 33.5 \\
\cline { 2 - 4 } & Female & 181 & 66.5 \\
\hline \multirow{3}{*}{ Age } & $18-26$ & 165 & 60.7 \\
\cline { 2 - 4 } & $27-35$ & 82 & 30.1 \\
\cline { 2 - 4 } & $36-44$ & 16 & 5.9 \\
\cline { 2 - 4 } & $45-54$ & 9 & 3.3 \\
\hline \multirow{4}{*}{\begin{tabular}{c} 
Position \\
\cline { 2 - 4 }
\end{tabular}} & Employed & 130 & 47.8 \\
\cline { 2 - 4 } & Student & 140 & 51.5 \\
\cline { 2 - 4 } $\begin{array}{c}\text { Purpose of } \\
\text { usage }\end{array}$ & Others & 2 & 0.7 \\
\cline { 2 - 4 } & Business & 21 & 7.7 \\
\cline { 2 - 4 } & Personal & 211 & 77.6 \\
\hline
\end{tabular}

TABLE III. RELIABILITY TEST, PEARSON CORRELATION R AND MULTIPLE REGRESSION

\begin{tabular}{|c|c|c|c|c|}
\hline \multirow{2}{*}{ Factors } & \multirow{2}{*}{$\begin{array}{c}\text { Cronbach } \\
\text { Alpha } \\
\text { N=272 }\end{array}$} & \multirow{2}{*}{$\begin{array}{c}\text { Pearson } \\
\text { Correlation, } r \\
\text { Behavioral } \\
\text { intention (BI) }\end{array}$} & \multicolumn{2}{|c|}{ Multiple Regression } \\
\hline & & & Beta & Sig. \\
\hline $\begin{array}{l}\text { Behavioral } \\
\text { intention (BI) }\end{array}$ & 0.93 & 1.000 & - & - \\
\hline $\begin{array}{l}\text { Social influence } \\
\text { (SI) }\end{array}$ & 0.89 & $.596 * *$ & - & - \\
\hline $\begin{array}{l}\text { Perceived } \\
\text { Usefulness } \\
\text { (PU) } \\
\end{array}$ & 0.94 & $.733 * *$ & 0.425 & .000 \\
\hline $\begin{array}{l}\text { Perceived ease } \\
\text { of use (PEU) }\end{array}$ & 0.93 & $.636^{* *}$ & 0.095 & .135 \\
\hline $\begin{array}{l}\text { Observability } \\
\text { (OBS) }\end{array}$ & 0.88 & $.574 * *$ & \multirow{2}{*}{0.184} & \multirow{2}{*}{.007} \\
\hline $\begin{array}{l}\text { Mobility } \\
\text { (MOB) }\end{array}$ & 0.92 & $.686 * *$ & & \\
\hline $\begin{array}{l}\text { Facilitating } \\
\text { condition (FC) } \\
\end{array}$ & 0.93 & $.602 * *$ & \multirow{3}{*}{.0174} & \multirow{3}{*}{.014} \\
\hline $\begin{array}{l}\text { Perceived } \\
\text { enjoyment (PE) }\end{array}$ & 0.93 & $.670^{* *}$ & & \\
\hline $\begin{array}{l}\text { Personalization } \\
(\mathrm{PN})\end{array}$ & - & $.512 * *$ & & \\
\hline
\end{tabular}

** Correlation is significant at the 0.01 level (2-tailed), Significant at: $\mathrm{p}<0.05$ 